\title{
Critical appraisal and update on tenofovir in management of human immunodeficiency virus infection
}

This article was published in the following Dove Press journal:

Virus Adaptation and Treatment

30 August 2011

Number of times this article has been viewed

\author{
Elena Alvarez' \\ Judit Morello' \\ Vincent Soriano 2 \\ Pablo Labarga ${ }^{2}$ \\ Sonia Rodriguez-Nóvoa' \\ 'Pharmacokinetic and \\ Pharmacogenetic Unit, Service \\ of Infectious Diseases, ${ }^{2}$ Department \\ of Infectious Diseases, Hospital \\ Carlos III, Madrid, Spain
}

\begin{abstract}
Tenofovir is currently one of the most widely used nucleoside reverse transcriptase inhibitors in the treatment of human immunodeficiency virus (HIV) due to its good efficacy, tolerability, and convenience as a once-daily dosage. It is a drug of choice both for first-line therapy in naïve and pretreated patients, along with two other active drugs as part of a highly active antiretroviral therapy. Moreover, tenofovir can be used to treat hepatitis B virus-infected patients as well as coinfected patients who meet criteria to be treated for HIV or hepatitis B virus infection, and more recently some studies have supported its use as part of pre-exposure prophylaxis. Although large clinical trials and postmarketing studies have shown a gentle renal profile for tenofovir, some prospective cohort studies and case reports have raised concern about renal damage and bone disorders associated with use of tenofovir in a small proportion of patients, and apprehension lingers over its long-term usage. Renal toxicity from tenofovir seems to be linked to tubular damage, so classical markers for monitoring renal function that mainly assess glomerular function would not be advisable to detect early renal impairment. Management of toxicity associated with tenofovir should be based on assessment of optimal biomarkers for the detection and monitoring of renal disease.
\end{abstract}

Keywords: tenofovir, antiretroviral treatment, kidney, human immunodeficiency virus, hepatitis B

\section{Introduction}

Tenofovir disoproxil fumarate (TDF), the first nucleotide analog approved for the treatment of human immunodeficiency virus (HIV) infection, was introduced a decade ago as part of the antiretroviral armamentarium. Since then, this drug has replaced most nucleoside analogs as the backbone of many antiretroviral combination regimens in the Western world, where lipoatrophy and other side effects of nucleoside analogs have become the major drawback of this drug family. The coformulation of tenofovir with emtricitabine (Truvada ${ }^{\circledR}$ ) or with emtricitabine and efavirenz (Atripla ${ }^{\circledR}$ ) as a single pill to be taken once daily has further increased the popularity of this drug. Other attractive features of TDF are its potent antiviral activity when compared with abacavir in subjects having high viral loads, its relatively high genetic barrier for resistance, and its activity against hepatitis $B$ virus, which makes the drug particularly attractive for treatment of individuals coinfected with HIV and hepatitis B virus. However, widespread use of the drug has allowed the recognition of some mild and long-term side effects in a subset of patients with prolonged TDF exposure, mainly associated with kidney tubular dysfunction and loss of bone density.
Correspondence: Sonia Rodriguez-Novoa Pharmacokinetic and Pharmacogenetic Unit, Service of Infectious Diseases, Hospital Carlos III, C/Sinesio Delgado I0, 28029 Madrid, Spain

Tel +34 4532694

Fax +34 4532696

Email sonia_r_novoa@hotmail.com 


\section{Treatment challenges in management of HIV infection}

Since the identification of HIV in $1983^{1,2}$ and until the approval of zidovudine in 1987, neither a cure nor long-term survival was expected for persons infected with the virus. During the years that followed, efforts were focused on developing more and better compounds against the virus. The nucleoside reverse transcriptase inhibitors, to which zidovudine belongs, were soon complemented with other molecules, such as didanosine, zalcitabine, stavudine, and lamivudine. However, it was not until the introduction of the protease inhibitors in 1996 that the expectations of antiretroviral therapy experienced a dramatic shift. Only then was it appreciated that triple combination therapy could provide unprecedented control of HIV replication, CD4 gain, and ultimately prolonged survival. The combination of three drugs, ie, two nucleoside reverse transcriptase inhibitors and one protease inhibitor or nonnucleoside reverse transcriptase inhibitor (NNRTI) is known as highly active antiretroviral therapy, and has become the paradigm for antiretroviral treatment.

TDF, a unique nucleotide analog and the first approved to treat HIV infection, was introduced to the market in 2001. Moreover, further drug families directed to other targets in the life cycle of the virus were developed, including NNRTIs and, more recently, the entry inhibitors and integrase inhibitors.

Nowadays, there are 25 drugs approved for the treatment of HIV infection. Some of these drugs are coformulated in combinations and allow once-daily dosage, thereby simplifying therapy and improving compliance. TDF is currently one of the most widely used nucleos(t)ide reverse transcriptase inhibitors in the treatment of HIV infection due to its excellent combination of good potency, tolerability, and convenience as a once-daily dosage. TDF is marketed either as a single agent $\left(\right.$ Viread $\left.^{\circledR}\right)$ or coformulated with emtricitabine, or with emtricitabine + efavirenz, the latter being the "gold standard" in patients initiating antiretroviral therapy. TDF + emtricitabine is also considered to be a combination of choice when antiretroviral therapy is initiated with a boosted protease inhibitor, and in patients with good virological control in whom an alternative nucleoside reverse transcriptase inhibitor has to be substituted to avoid or reverse toxicity. More recently, TDF + raltegravir (the first integrase inhibitor marketed) has been included as an option for initial therapy because it is very effective in terms of virological suppression and CD4 gain, as well as having a good safety profile. In this review we summarize the most relevant aspects of TDF use.

\section{Pharmacology}

TDF is the fumarate salt of the prodrug, tenofovir. Following gastrointestinal absorption, tenofovir disoproxil undergoes initial diester hydrolysis and is transformed into tenofovir, a nucleotide analog of adenosine monophosphate, and subsequently undergoes phosphorylation by cellular enzymes to form the active compound, tenofovir diphosphate. Tenofovir diphosphate inhibits HIV reverse transcriptase by competing with the natural substrate, deoxyadenosine 5'-triphosphate, causing DNA chain termination. The in vitro anti-HIV 50\% inhibitory concentration $\left(\mathrm{IC}_{50}\right)$ is in the range of $1-6 \mu \mathrm{M} .{ }^{3,4}$

TDF has a low bioavailability of $25 \%$ in the fasted state. Administration of TDF with a high-fat meal enhances its bioavailability by $40 \%$. Thus, it is recommended that TDF be administered with food. After oral administration, tenofovir is minimally bound to plasma proteins and distributed to most tissues, with the highest concentrations occurring in the kidney, liver, and intestine. In vitro studies have shown that neither TDF nor tenofovir are substrates for the cytochrome P450 (CYP) enzymes. Moreover, tenofovir does not inhibit in vitro drug metabolism mediated by any of the major human CYP450 isoforms, so it is unlikely that clinically significant interactions involving tenofovir and drugs metabolized by CYP450 would occur. The terminal half-life of tenofovir in plasma is approximately $12-18$ hours. It is primarily excreted via the kidney by both glomerular filtration and active tubular secretion. ${ }^{3}$ Regarding the pathway of active tubular secretion, tenofovir enters the proximal tubule cells via human organic anion transporters 1 and $3^{5,6}$ and is excreted into the urine by multidrug resistant protein 4; the role of MRP2 and MRP7 in this process is under study (Figure 1) $\cdot^{7-12}$ Coadministration of TDF and drugs that reduce renal function or compete for active tubular secretion via transport proteins, human organic anion transporters, or multidrug resistant proteins (eg, cidofovir and didanosine $)^{13}$ may increase serum concentrations of TDF and/or the coadministered drug. TDF should not be coadministered with nephrotoxic agents, ie, the aminoglycosides, amphotericin B, foscarnet, ganciclovir, pentamidine, vancomycin, cidofovir, or interleukin-2. ${ }^{3}$

Pharmacokinetic studies have demonstrated that coadministration of TDF and protease inhibitors results in increased tenofovir exposure, probably due to increased absorption ${ }^{14-17}$ or to a reduction in renal clearance of tenofovir, ${ }^{18,19}$ but this seems not to be clinically relevant. However, coadministration of TDF and didanosine is not recommended. Although didanosine has no effect on the pharmacokinetics of TDF, didanosine exposure increases by $40 \%-60 \%$, increasing the risk of didanosine-related side effects. ${ }^{20-22}$ Further, increased 
exposure to didanosine could enhance the mitochondrial toxicity of TDF to the kidneys, and may account for the greater risk of renal toxicity in patients treated with a combination of TDF and didanosine. ${ }^{23}$

\section{Clinical experience with tenofovir}

The efficacy and safety of TDF has been evaluated in multiple clinical trials conducted in both treatment-naïve and antiretroviral-experienced patients (Table 1). In two prospective, randomized, controlled trials (903 and 934) that evaluated the efficacy and safety of TDF vs either stavudine or zidovudine in combination with efavirenz and lamivudine or emtricitabine in antiretroviral-naïve patients over 144 weeks, the TDF arm demonstrated greater and more prolonged effectiveness in terms of viral suppression and CD4 gain. ${ }^{24-27}$ Similar results were observed in two placebo-controlled studies (902 and 907) which included HIV treatment-experienced individuals with detectable viral load on stable combination antiretroviral therapy. ${ }^{28,29}$

Tenofovir + emtricitabine and abacavir + lamivudine are fixed-dose combinations commonly used along with NNRTIs or ritonavir-boosted protease inhibitors as firstline therapy, but there is conflicting evidence concerning their relative efficacy. Several trials have suggested higher efficacy for TDF + emtricitabine, ${ }^{30-32}$ especially in the subset of patients with high viral load, whereas other studies have shown no difference in efficacy when comparing these nucleoside reverse transcriptase inhibitor backbones through 96 weeks. ${ }^{33-35}$ Lack of human leucocyte antigen (HLA) B*5701 allele determination in patients who initiated abacavir in some of these studies might explain these different results.

Antiretroviral therapy failure can be caused by selection of resistance mutations that decrease susceptibility to a specific antiretroviral drug. The signature mutation for tenofovir is $\mathrm{K} 65 \mathrm{R}$, which is associated with a modest decrease in sensitivity to tenofovir in vitro, although K65R selection occurs infrequently in tenofovir-treated patients. ${ }^{36}$ This mutation may also be selected for by prior treatment with nucleoside analogs, such as didanosine, abacavir, stavudine, and lamivudine, ${ }^{37}$ thus leading to potential crossresistance among these drugs. TDF should be avoided in antiretroviral-experienced patients with strains harboring the K65R mutation. ${ }^{38}$ Simultaneous presence of the lamivudineassociated $\mathrm{M} 184 \mathrm{~V}$ reverse transcriptase mutation and K65R further reduces the replicative capacity of the virus. TDF resistance is also associated with thymidine analog resistance mutations. The presence of three or more thymidine analog resistance mutations has been associated with a decreased response to tenofovir, particularly if these mutations include M41L or L210W. ${ }^{37}$

With regard to adverse effects, TDF has not shown the mitochondrial toxicity linked with other nucleoside reverse transcriptase inhibitors. Moreover, TDF has a low risk of lipoatrophy and a favorable effect on the lipid profile compared with the older nucleoside analog agents, such as stavudine or zidovudine..$^{24-27,39}$ Nevertheless, when comparing TDF + emtricitabine vs abacavir + lamivudine, greater increases in bone turnover and decreases in bone density were observed in subjects treated with TDF + emtricitabine. ${ }^{30,33,40}$ No difference in estimated glomerular filtration rate between the treatment arms was reported, but increases in tubular dysfunction markers were observed in the TDF + emtricitabine arm. ${ }^{32,35}$ In the abacavir group, serious (Grade 3/4) adverse events occurred more frequently and earlier than in the TDF group, and were likely related to hypersensitivity reactions to abacavir. Furthermore, abacavir regimens were associated with more serious events unrelated to acquired immunodeficiency syndrome, particularly cardiovascular events. ${ }^{30,32,33}$ TDF is frequently administered in combination with protease inhibitors. Most regimens offer comparable levels of virological efficacy, ${ }^{15,24,41-45}$ so selection of the regimen will be based on tolerability and convenience of the drugs in order to improve adherence and outcomes of therapy.

\section{Tenofovir-associated renal toxicity}

Only $1 \%-2 \%$ of HIV-infected adults receiving TDF show signs of nephrotoxicity. ${ }^{46-50}$ In many prospective clinical trials that have compared patients exposed to TDF vs other antiretroviral drugs, renal safety assessed by glomerular filtration rate was found to be similar in both groups of patients. ${ }^{24,26,27}$ In addition, some case-control and cohort studies have described no significant renal dysfunction associated with TDF use in clinical practice. ${ }^{46,47,50,51}$ However, other studies have found a greater increase in serum creatinine and a modest decline in creatinine clearance in subjects treated with TDF vs patients not exposed to TDF. ${ }^{52-59}$ Moreover, in some of these studies, development of renal injury has been attributed to underlying causes unrelated to TDF use. ${ }^{47,50,51}$ Nevertheless, it is noteworthy that patients in whom TDF was related to a decline in renal function were on protease inhibitor-based regimens. Coadministration of protease inhibitors and TDF is known to increase TDF exposure and thereby the potential nephrotoxic effect of TDF. ${ }^{14-19}$ The influence of protease inhibitors on the renal safety profile of TDF has been evaluated in several studies. ${ }^{14,18,19,53,54}$ Although one study found a greater decrease in renal function with protease inhibitors, ${ }^{54}$ most agreed that 


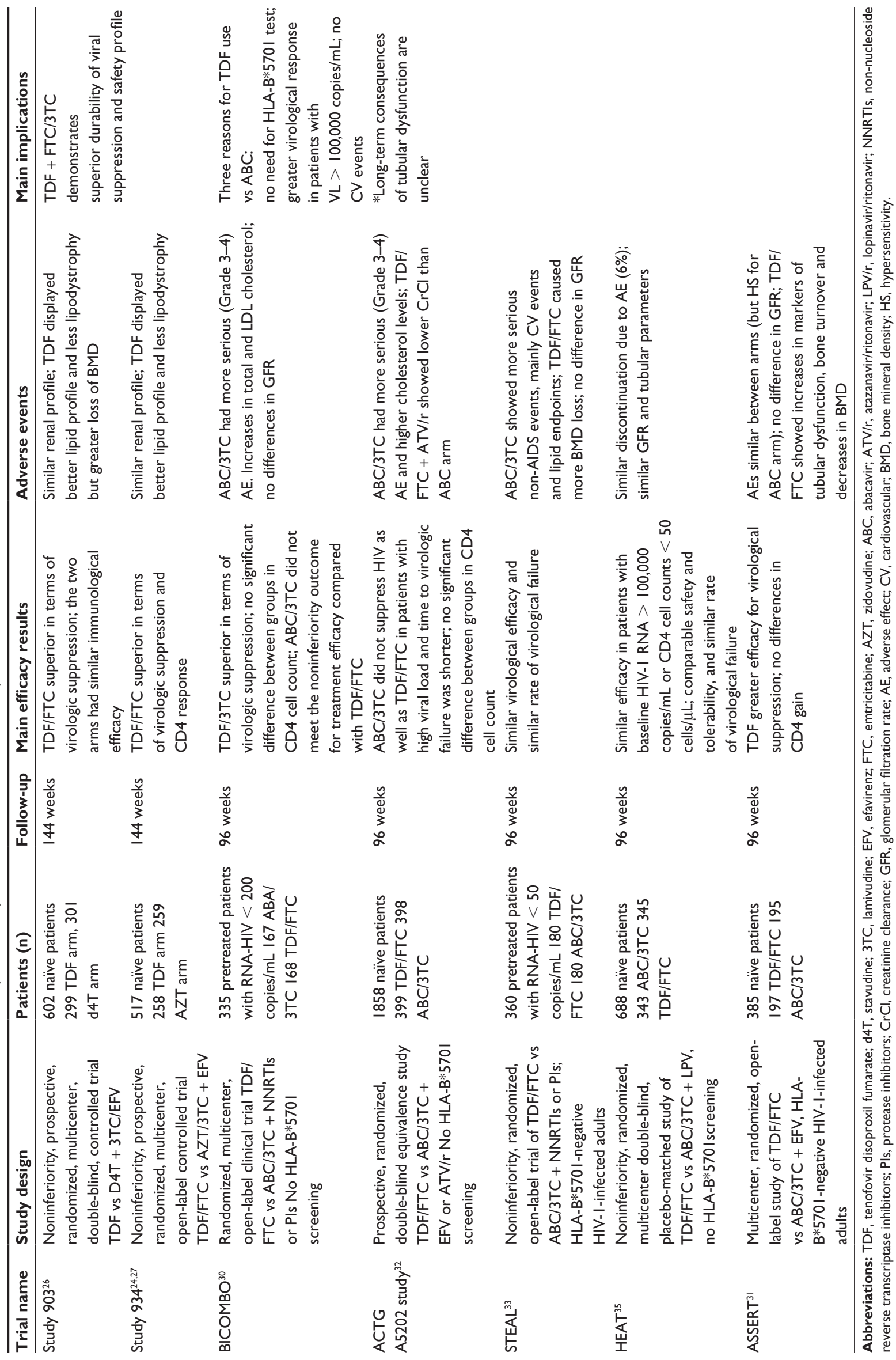


the combination of TDF and a protease inhibitor was safe and well tolerated. ${ }^{14,19,53}$

In addition to the data derived from these studies, a large number of case reports have raised concern about cases of renal damage in patients with normal glomerular filtration rate exposed long-term to TDF (Table 2). While some individuals presented with acute renal failure, ${ }^{48,60-67}$ most subjects initially showed tubulopathy, occasionally with overt Fanconi syndrome. ${ }^{68-78}$ An early sign of tubular dysfunction is hypophosphatemia, although other signs and symptoms of kidney tubulopathy include glucosuria with normal serum glucose levels, mild proteinuria, acidosis, and hypokalemia. A subset of individuals may show evidence of nephrogenic diabetes insipidus. ${ }^{68-72,76}$ The chronic consequences of significant loss of phosphate, proteins, and glucose are currently unknown, but are worrisome for an increased risk of premature osteoporosis and osteomalacia. ${ }^{79,80}$ In addition, some studies have suggested a link between TDF use, secondary hyperparathyroidism, and low vitamin D levels, which also lead to a greater risk of osteopenia and osteoporosis. ${ }^{81,82}$

In spite of some studies having reported that impaired renal function related to TDF use generally improved after TDF discontinuation, ${ }^{48,61,70,72,83}$ in some cases renal function did not fully recover, although renal damage did not progress. ${ }^{84,85}$ Those studies in which renal function improved after TDF withdrawal have often been based on short-term follow-up or have looked only at creatinine clearance, a marker of glomerular disease that may not detect abnormalities in renal tubular function.

It is noteworthy that even though TDF is not yet licensed for use in HIV-infected individuals younger than 18 years of age, it is often used off-label in this age group as part of a salvage regimen. As with adults, some cases of proximal renal tubular dysfunction and bone disorders have been reported. ${ }^{85-90}$ Bone density loss tends to occur more often in less skeletally mature children, who are at higher risk of growth disorders. Because children are likely to take antiretroviral therapy for longer than adults, and are more prone to long-term toxicity related to TDF use, alternative TDF dosing regimens and careful monitoring of bone density and renal function is indicated in the pediatric and adolescent population.

The most frequent risk factors for developing TDF-induced nephrotoxicity include baseline renal dysfunction, a low CD4 count, older age, and low body weight. ${ }^{47,50,91}$ Classical risk factors associated with renal damage in HIV patients, such as pre-existing systemic conditions, HIV itself, antiretroviral therapy, or use of nephrotoxic agents, may also enhance the potential risk of nephrotoxicity associated with TDF. ${ }^{91,92}$
More recently, TDF-associated renal proximal tubulopathy has been linked to genetic variants in transporter proteins involved in tenofovir excretion (Figure 1). ${ }^{93}$ Polymorphisms in these genes would lead to intracellular accumulation of tenofovir. This is the case for polymorphisms in the $A B C C 2$ gene which encodes for MRP2. The haplotype CATC (defined as the combination of the polymorphisms at positions-24, $1249,3563$, and 3972) $)^{94}$ and the allele $-24 C^{95}$ have been associated with an increased risk of TDF-associated tubulopathy. Moreover, MRP4, coded by the $A B C C 4$ gene, is also implicated. The 669-C $>\mathrm{T}$ polymorphism at the $A B C C 4$ gene has been found to be more frequent in patients sustaining renal tubular damage, ${ }^{94}$ although this finding has not been confirmed by others. ${ }^{95}$ The rs9349256 polymorphism at the $A B C C 10$ gene that encodes for MRP7 has recently also been associated with urine phosphate wasting and $\beta_{2}$-microglobulinuria, which are indicative of renal tubular dysfunction. ${ }^{12}$ Currently, information about the effect of genetic polymorphisms on the risk of renal toxicity using TDF is a matter of controversy and requires further examination.

Few studies have examined the association between tenofovir exposure and renal toxicity. In most cases, patients developing tubulopathy had tenofovir levels above the concentration expected according to pharmacokinetic studies done in HIV-infected patients..$^{74,76,96}$ In a recent study, patients with tubulopathy displayed significantly higher tenofovir plasma concentrations than patients with normal tubular function. The threshold established to define tubulopathy in this study was above $160 \mathrm{ng} / \mathrm{mL} .{ }^{97}$ These results suggest an association between tenofovir plasma exposure and TDFassociated renal toxicity, primarily recognizable as tubular dysfunction. If these data are confirmed, the quantitation of tenofovir plasma levels could be useful in the management of patients.

\section{Tenofovir and bone mineral loss}

According to the HIV Outpatient Study, HIV-infected persons seem to experience bone fractures more frequently than people without HIV and, moreover, the decline in bone density seems to be accelerated in $\mathrm{HIV}$-infected persons. ${ }^{98,99} \mathrm{HIV}$ infection in itself induces inflammation, which may result in accelerated loss of bone mineral density. On the other hand, antiretroviral therapy and some drugs in particular may increase the loss of bone mineral density. In the SMART (Strategies for Management of Anti-Retroviral Therapy) study, 240 HIV patients were randomized either to continue antiretroviral treatment or to interrupt it guided by CD4 cell counts. In patients who continued to be treated, bone mineral density decreased by 


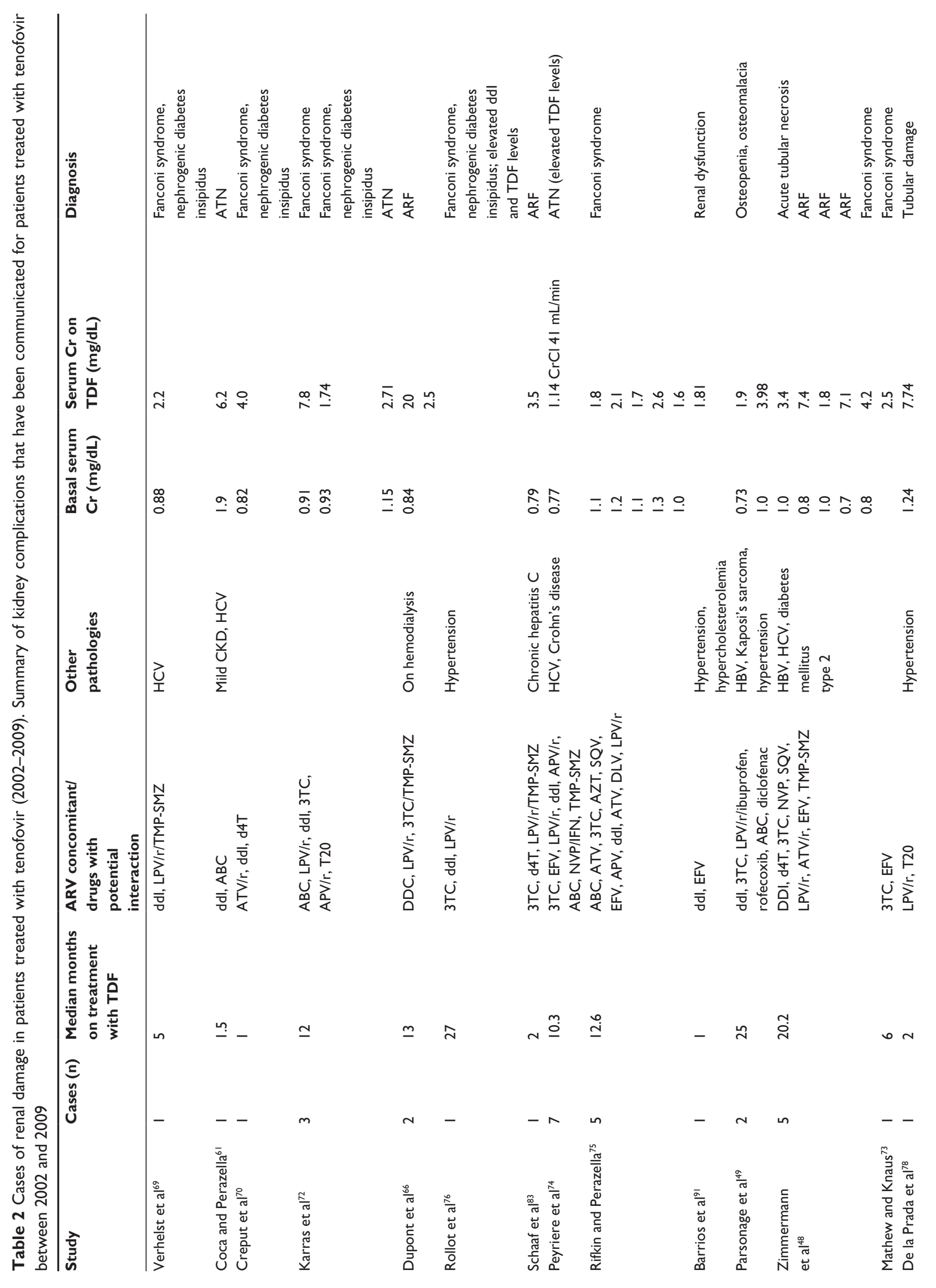



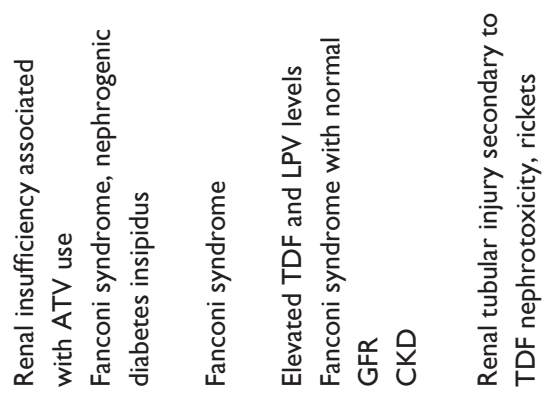

$>-$

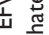

产

4

든 은

ชั ํํำ

$\sum_{n}^{N}$

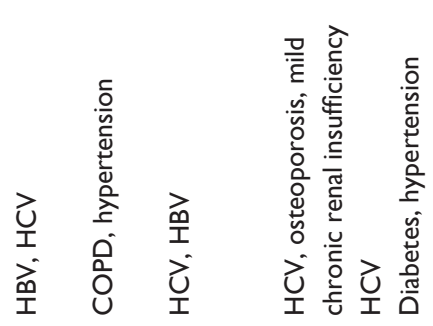

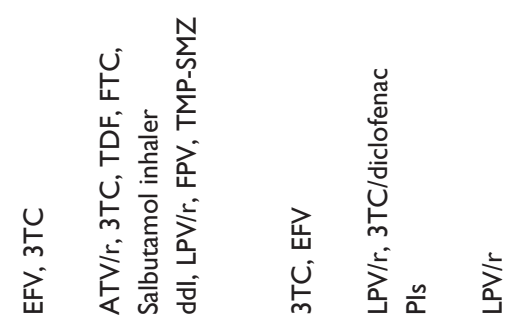

○ ก ก

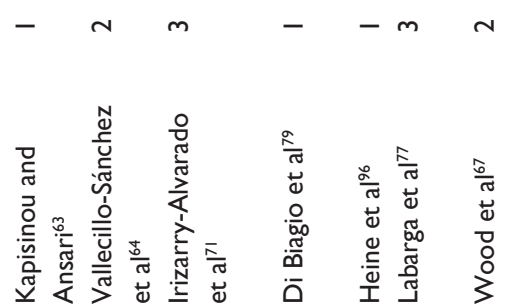

$0.8 \%$ per year at the hip $(P<0.001)$ and $0.4 \%(P=0.04)$ or $2.4 \%(P<0.001)$ at the spine (depending on the technique used, ie, either dual-energy radiographic absorptiometry or quantitative computed tomography). In contrast, bone mineral density remained stable or increased after 1 year in the group in which antiretroviral therapy was interrupted. ${ }^{100}$ Several clinical trials have shown that certain antiretrovirals may have a greater impact than others on loss of bone density. Although initially the protease inhibitors were thought to be associated with the greatest amount of bone loss, ${ }^{101}$ more recent studies have failed to confirm this association. ${ }^{102}$ Nevertheless, TDF use has been consistently associated with a decrease in bone density. Among other studies supporting this link are the 903 trial, ${ }^{26}$ ASSERT, ${ }^{31,40}$ and STEAL (Simplification with Tenofovir-Emtricitabine or Abacavir-Lamivudine). ${ }^{33}$ In all of these studies, patients receiving TDF had higher rates of bone density loss than those randomized to receive either stavudine or abacavir (Table 3). TDF use is associated with higher rates of renal tubular dysfunction compared with other nucleoside reverse transcriptase inhibitors, ${ }^{56,77}$ the phosphate loss associated with this damage being the primary driver of loss of bone density.

Parathyroid hormone is the major systemic determinant of bone turnover. Elevations in parathyroid hormone result in bone mineral loss. ${ }^{103}$ In HIV patients on antiretroviral treatment, parathyroid hormone elevations have been reported in up to $20 \%-40 \%$ of cases. ${ }^{81}$ In a recent study conducted in 564 HIV patients, some of whom received TDF and others did not, $44 \%$ vs $24 \%$, respectively $(P<0.001)$ developed hyperparathyroidism over 71 months. Moreover, a significant decrease in plasma calcium levels was observed in the TDF group, ${ }^{104}$ which might explain the elevation in parathyroid hormone.

Vitamin D deficiency causes parathyroid hormone elevations in the general population. ${ }^{105}$ This deficit can occur in up to $37 \%$ of patients with HIV infection. ${ }^{106}$ Vitamin D deficiency causes greater parathyroid hormone elevations in patients treated with TDF than in those treated with other nucleoside reverse transcriptase inhibitors. ${ }^{82}$ However, in TDF-treated patients, parathyroid hormone elevations may not only depend on vitamin $\mathrm{D}$ deficiency, given that similar vitamin $\mathrm{D}$ levels, measured as $25(\mathrm{OH}) \mathrm{D}_{3}$ and $1,25(\mathrm{OH})_{2} \mathrm{D}_{3}$, are seen in patients treated with and without TDF. ${ }^{104,107}$ Activation of $25(\mathrm{OH}) \mathrm{D}_{3}$ into $1,25(\mathrm{OH})_{2} \mathrm{D}_{3}$, which is the active form of vitamin $\mathrm{D}$, takes place in the proximal tubule of the nephron and is stimulated by parathyroid hormone. Given that TDF may cause tubular damage, impaired activation of $25(\mathrm{OH}) \mathrm{D}_{3}$ may occur, which subsequently may decrease the intestinal absorption of calcium, leading to a greater parathyroid hormone increase in an 


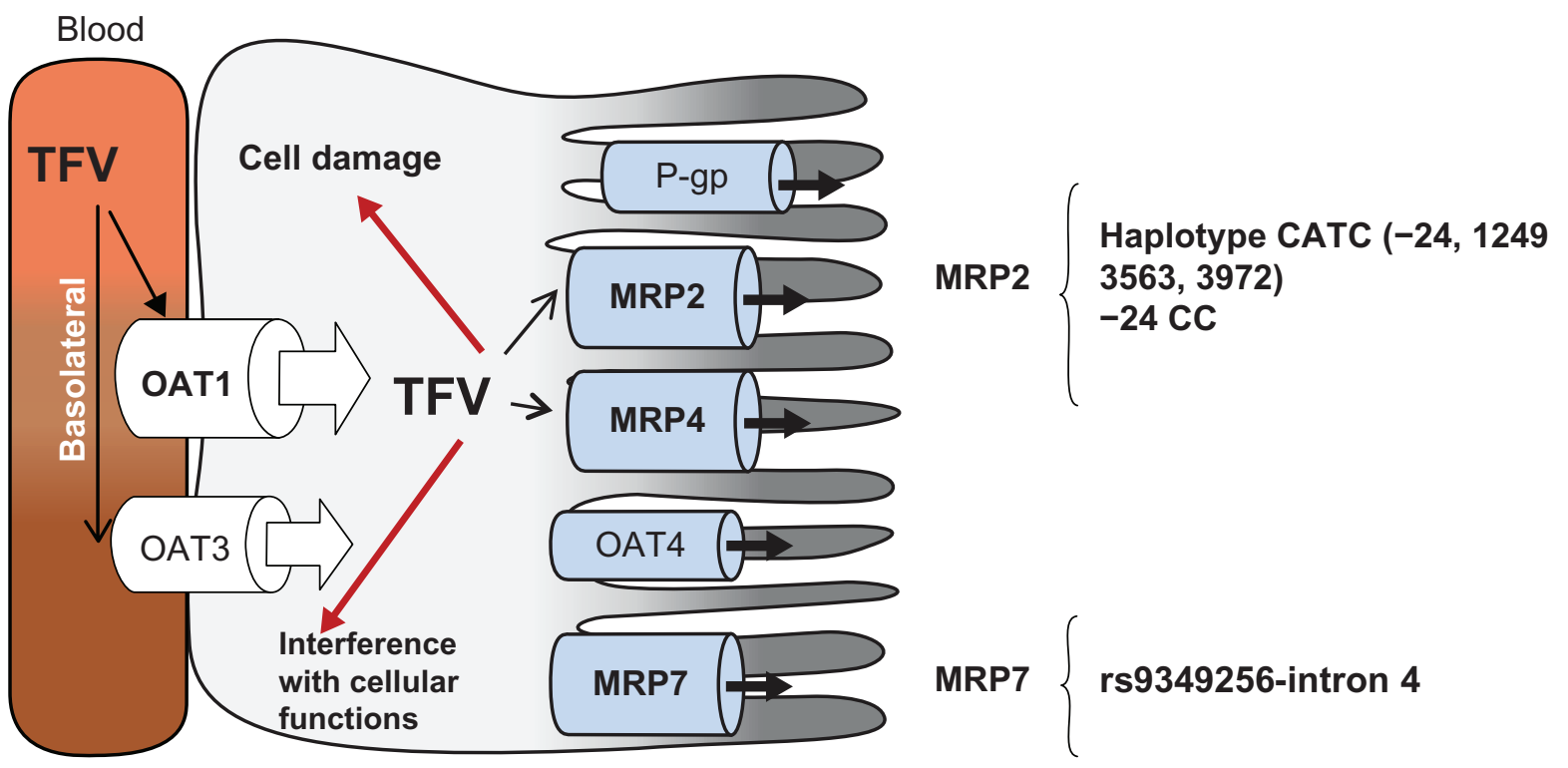

Renal tubular cell

Figure I Main transporter proteins involved in elimination of tenofovir from tubular renal cells. TFV enters kidney cells using OATI and in a lesser extent, OAT3 and it is eliminated by MPR4. Genetic polymorphisms in transporter proteins may influence the elimination of TFV. The more relevant polymorphisms associated with tubulopathy are listed on the right side of the figure.

Abbreviations: TFV, tenofovir; OATI, organic anion transporter protein-I; OAT3, organic anion transporter protein-3; MRP4, multidrug resistant protein-4; MRP2, multidrug resistant protein-2; MRP7, multidrug resistant protein-7.

attempt to correct this imbalance. Whatever the mechanism, it seems clear that patients treated with TDF have an imbalance between parathyroid hormone, vitamin $\mathrm{D}$, and calcium in plasma. Recognition of this abnormality has provided a rationale for empiric administration of vitamin $\mathrm{D}$ to patients treated with TDF. Although a decrease in parathyroid hormone levels may occur, it happens regardless of baseline
$25(\mathrm{OH}) \mathrm{D}_{3}$ levels, something that is not seen in patients who do not receive TDF. ${ }^{108}$

\section{Tenofovir for prevention of HIV infection}

The recent publication of two trials, ie, CAPRISA (Centre for the AIDS Program of Research in South Africa) ${ }^{109}$ and

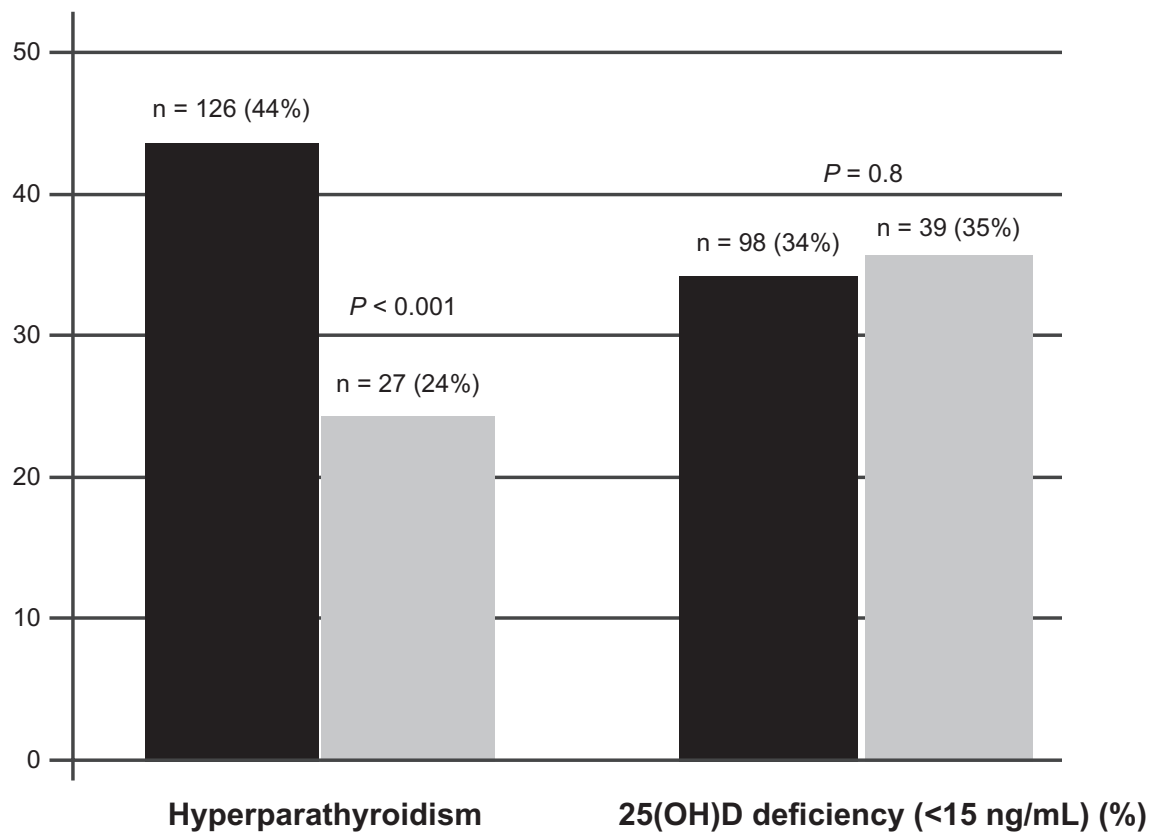

Figure 2 Prevalence of hyperparathyroidism and 25-hydroxyvitamin D deficiency according to TDF use. Light grey bars represent TDF users while the black ones represent those patients not taking TDF. Frequency of hyperparathyroidism differs significantly among TDF and non-TDF users, whereas no difference was found for $25(\mathrm{OH}) \mathrm{D}$ levels between groups. 
Table 3 Most relevant studies that have examined bone parameters in subjects with HIV treated by TDF vs patients not exposed to TDF

\begin{tabular}{|c|c|c|c|c|}
\hline $\begin{array}{l}\text { Study } \\
\text { (reference) }\end{array}$ & $\begin{array}{l}\text { Comparative } \\
\text { groups }\end{array}$ & Patients (n) & $\begin{array}{l}\text { Bone-related } \\
\text { parameters }\end{array}$ & Main findings \\
\hline Study $903^{26}$ & TDF vs d4T $+3 \mathrm{TC} / \mathrm{EFV}$ & 299 TDF 30I d4T & $\begin{array}{l}\text { Change in BMD } \\
\text { Lumbar spine: }-2.2 \% \text { TDF } \\
\text { vs }-1.0 \% \mathrm{~d} 4 \mathrm{~T} ; P=0.0 \mathrm{I} \\
\text { Hip: }-2.8 \% \text { TDF vs }-2.4 \% \mathrm{~d} 4 \mathrm{~T} \text {; } \\
P=0.06\end{array}$ & $\begin{array}{l}\text { Greater loss of BMD in the } \\
\text { TDF arm }\end{array}$ \\
\hline ASSERT study ${ }^{31,40}$ & $\begin{array}{l}\text { TDF/FTC vs ABC/ } \\
3 \mathrm{TC}+\mathrm{EFV}\end{array}$ & $\begin{array}{l}197 \text { TDF/FTC } 195 \\
\text { ABC/3TC }\end{array}$ & $\begin{array}{l}\text { Change in BMD: } \\
\text { Lumbar spine: }-2.4 \% \text { TDF } \\
\text { vs }-1.6 \% A B C ; P=0.036 \\
\text { Hip: }-3.6 \% \text { TDF vs }-1.6 \% A B C \text {; } \\
P<0.00 \text { I. } \\
\text { BMD loss }>6 \text { : } \\
\text { I } 3 \% \text { TDF vs } 3 \% A B C \text { in the hip. } \\
\text { 10\% TDF vs } 5 \% A B C \text { in the spine }\end{array}$ & $\begin{array}{l}\text { TDF/FTC: Increases } \\
\text { in markers of tubular } \\
\text { dysfunction, bone turnover } \\
\text { and decreases in BMD }\end{array}$ \\
\hline STEAL study ${ }^{33}$ & $\begin{array}{l}\text { TDF/FTC vs ABC/3TC }+ \\
\text { NNRTIs or Pls }\end{array}$ & $\begin{array}{l}\text { I80 TDF/FTC } 180 \\
\text { ABC/3TC }\end{array}$ & $\begin{array}{l}\text { Mean difference in hip t score, } \\
0.16 ; 95 \% \mathrm{Cl}: 0.08-0.23 ; P<0.00 \mathrm{I} \\
\text { Rates of bone disorders: } 8.5 \mathrm{TDF} \\
\text { vs } 4.4 \mathrm{ABC} ; P=0.0032\end{array}$ & $\begin{array}{l}\text { Greater loss of BMD in the } \\
\text { TDF arm }\end{array}$ \\
\hline $\begin{array}{l}\text { Kinai and } \\
\text { Hanabusa }^{56}\end{array}$ & TDF vs other NRTI & 40 TDF $23 \mathrm{NRTI}$ & $\begin{array}{l}\text { Change in \% TRP from baseline to } 96 \\
\text { weeks: } \\
94 \text { to } 90 \% P=0.04 \text { TDF } \\
96 \text { to } 94 \% P=0.33 \text { NRTI }\end{array}$ & $\begin{array}{l}\text { Consider close monitoring } \\
\text { or TDF discontinuation if } \\
\text { persistent decline of \% TRP }\end{array}$ \\
\hline Labarga et al ${ }^{77}$ & TDF vs non-TDF & $\begin{array}{l}\text { I54 TDF } 49 \text { non-TDF } \\
\text { I8I naïve }\end{array}$ & $\begin{array}{l}\text { TRP rate in TDF vs non-TDF and } \\
\text { naïve: } 0.82,0.85 \text { and } 0.87\end{array}$ & $\begin{array}{l}\text { Close monitoring of } \\
\text { accelerated bone mineral } \\
\text { loss and renal insufficiency }\end{array}$ \\
\hline Rosenvinge et $\mathrm{al}^{82}$ & TDF vs non-TDF & I08 TDF 86 non-TDF & $\begin{array}{l}\text { PTH levels: } 7.2 \text { TDF vs } 4.3 \\
\text { non-TDF }(\mathrm{pg} / \mathrm{mL}) \\
\text { PTH in VVD (<50 nmol/L): } 8.2 \\
\text { TDF vs } 4.6 \text { non-TDF }(\mathrm{pg} / \mathrm{mL})\end{array}$ & $\begin{array}{l}\text { VDD is associated with TDF } \\
\text { linked Hyper-PTH }\end{array}$ \\
\hline Pocaterra et al ${ }^{107}$ & TDF vs non-TDF & 214 TDF 232 Pls & $\begin{array}{l}\text { Overall: } \\
\text { I } 7.5 \% \text { patients Hyper-PTH } \\
(\mathrm{ULN}=65 \mathrm{pg} / \mathrm{mL}) \\
77.4 \% \text { patients VDD }(<30 \mathrm{mg} / \mathrm{dL}) \\
\text { TDF group: } \\
75.4 \% \text { PTH }>65 \text { vs } 55.9 \% \\
\text { PTH }<65 \text { in TDF group, } \\
P=0.002\end{array}$ & $\begin{array}{l}\text { Association between hyper- } \\
\text { PTH, TDF use and } 25(\mathrm{OH}) \mathrm{D} \\
\text { levels beside classical factors }\end{array}$ \\
\hline Labarga et al ${ }^{104}$ & TDF vs non-TDF & 433 TDF I3I non-TDF & $\begin{array}{l}\text { Hyper-PTH: } 37 \% \text { TDF vs I } 4 \% \\
\text { non-TDF; } P<0.00 \text { I } \\
\text { Hyper-PTH + VDD ( }<15 \mathrm{ng} / \mathrm{mL}) \text { : } \\
44 \% \text { TDF vs I0\% non-TDF; } \\
P<0.00 \text { I }\end{array}$ & $\begin{array}{l}\text { Hyper-PTH and bone } \\
\text { resorption might develop } \\
\text { in the subset of patients } \\
\text { taking TDF with suboptimal } \\
25(\mathrm{OH}) \mathrm{D} \text { levels }\end{array}$ \\
\hline Childs et $\mathrm{a}^{81}$ & TDF vs non-TDF & 45 HAART & $\begin{array}{l}\text { PTH levels: } 80 \mathrm{pg} / \mathrm{mL} \text { TDF vs } \\
55 \mathrm{pg} / \mathrm{mL} \text { non-TDF; } P=0.02 \\
\text { In VDD ( }<30 \mathrm{ng} / \mathrm{mL}) \text { : PTH elevated } \\
\text { in } 41 \% \text { TDF vs } 0 \% \\
\text { non-TDF; } P=0.018\end{array}$ & $\begin{array}{l}\text { Use of TDF and the } \\
\text { level of } 25(\mathrm{OH}) \mathrm{D} \text { were } \\
\text { independently associated } \\
\text { with PTH levels }\end{array}$ \\
\hline
\end{tabular}

Abbreviations: TDF, tenofovir disoproxil fumarate; d4T, stavudine; 3TC, lamivudine; EFV, efavirenz; FTC, emtricitabine; ABC, abacavir; NNRTIs, non-nucleoside reverse transcriptase inhibitors; Pls, protease inhibitors; NRTI, nucleoside reverse transcriptase inhibitors; PL, placebo; BMD, bone mineral density; TRP, tubular reabsorption of phosphate; PTH, parathyroid hormone; hyper-PTH, hyperparathyroidism; ULN, upper limit of normal; VDD, vitamin D deficiency.

iPrEX (Pre Exposure Prophylaxis Initiative) ${ }^{110}$ has raised unprecedented interest in pre-exposure prophylaxis as a way to combat the HIV pandemic. CAPRISA examined nearly 900 heterosexually active women in South Africa and demonstrated that use of topical vaginal TDF reduced the risk of
HIV acquisition by $39 \%$ overall, rising to $54 \%$ in the subset of women with high gel adherence.

The iPrEX trial examined nearly 2500 homosexual men in South America, South Africa, Thailand, and the US, and was the first to show that daily oral TDF + emtricitabine 
could reduce the risk of HIV infection by $44 \%$ overall, increasing to $73 \%$ in the subset of men with sustained good drug adherence.

These trial results have been greeted with huge enthusiasm, especially in the wake of disappointing results from several prior studies, but have also raised numerous questions about who could potentially benefit, the long-term risks of these interventions, and cost and access issues. Moreover, antiretroviral use for preventing infection in HIV-seronegative individuals at risk must be considered in the context of other interventions that may help equally to reduce HIV acquisition.

While Truvada has not been approved so far for HIV prevention, doctors may prescribe drugs for off-label use, and some individuals engaged in high-risk behaviors might consider immediate use of the drug as pre-exposure prophylaxis. For these reasons, on January 28, 2011, the Centers for Disease Control and Prevention (CDC) released new guidance intended to offer instructions and cautions for people interested in using pre-exposure prophylaxis immediately, while awaiting more extensive clinical trial data for longer-term use and other at-risk populations. The CDC guidance is available at: http://www.cdc.gov/nchhstp/ newsroom/PrEPMSMGuidanceGraphic.html.

Briefly, the CDC recommendations for pre-exposure prophylaxis are:

- Confirm that the person seeking pre-exposure prophylaxis is at substantial ongoing high risk for acquiring HIV infection

- Test for HIV, including, if symptomatic, acute HIV infection that may not be detectable with a standard antibody test, given that using just two antiretroviral drugs could lead to resistance if HIV is present; repeat HIV testing every 3 months while on pre-exposure prophylaxis

- Screen for and treat other sexually transmitted diseases, including syphilis, gonorrhea, hepatitis B and C, and repeat testing every 6 months while on pre-exposure prophylaxis

- Test for kidney function (creatinine clearance), because tenofovir may produce renal injury in some individuals, and monitor kidney function after 3 months and then annually while on pre-exposure prophylaxis

- Screen for, and if uninfected, vaccinate against hepatitis $\mathrm{B}$; if infected, consider the dual use of Truvada for treatment, because TDF and emtricitabine are both active against $\mathrm{HBV}$ and HIV

- Provide pre-exposure prophylaxis as part of a comprehensive prevention approach, along with risk-reduction counseling and condoms; assess risk behavior every 3 months while on pre-exposure prophylaxis

- Stress importance of and offer support for drug adherence.

It should be kept in mind that the iPrEX trial did not provide evidence that using Truvada only before or after sex encounters is effective. Pre-exposure prophylaxis has the potential to contribute to effective and safe HIV prevention for homosexual men engaged in high-risk behaviors, but its maximal cost-effectiveness will be obtained taking into consideration a number of factors, including the following:

- Homosexual men at high-risk for HIV acquisition need to be targeted

- Pre-exposure prophylaxis must be delivered as part of a comprehensive set of prevention services, including risk-reduction and medication adherence counseling, ready access to condoms, and diagnosis and treatment of sexually transmitted diseases

- Monitoring of HIV status, side effects, adherence, and risk behaviors at regular intervals is mandatory.

Finally, all these efforts for helping to reduce HIV acquisition must be accompanied by appropriate information and education about safer lifestyles, particularly high-risk sexual practices.

\section{Tenofovir for hepatitis B treatment}

TDF was licensed in 2008 for the treatment of hepatitis B infection. It is a potent inhibitor of hepatitis B virus reverse transcriptase, with an $\mathrm{IC}_{50}$ of $0.14-1.5 \mu \mathrm{M} .{ }^{3} \mathrm{TDF}$ along with entecavir are currently the preferred first-line choices for treatment in hepatitis B-monoinfected patients. TDF has been demonstrated to be effective either in nucleos(t)ide analogs-naïve patients or in patients with prior resistance to lamivudine and/or adefovir, although in the latter situation the response tends to be lower. ${ }^{111-113}$

Of 350 million people worldwide infected with the hepatitis B virus, approximately four million are coinfected with HIV. HIV modifies the natural history of the hepatitis B virus, favoring chronification and accelerating progression to cirrhosis and end-stage liver disease. ${ }^{114}$ In patients who need to be treated for either HIV or hepatitis B virus infection, early initiation of antiretroviral treatment, including drugs active against hepatitis B virus (lamivudine, emtricitabine, TDF) is recommended. At this time, TDF is preferred to lamivudine as the only active anti-hepatitis B virus agent in this context, given its higher genetic barrier to resistance. Thus, the coformulation of TDF + emtricitabine is the most popular nucleoside reverse transcriptase inhibitor backbone 
in coinfected patients. ${ }^{115}$ Because prolonged TDF exposure may cause kidney dysfunction in a small proportion of treated individuals, renal function should be carefully and periodically monitored in individuals coinfected with HIV and hepatitis B virus.

\section{Patient-focused perspectives}

The availability of highly active antiretroviral therapy has markedly improved survival rates and quality of life in patients infected with HIV. The natural history of HIV infection has been changed into a manageable chronic disease requiring long-term antiretroviral treatment. Because patients need to continue their treatment lifelong, the preferred antiretroviral regimen will be one that, along with efficacy, optimizes the likelihood of patient compliance. One strategy to improve adherence is to facilitate the intake of medication, for example, by reducing the pill burden, including drugs that allow once-daily dosage or those with no food restrictions.

Antiretroviral drugs are characterized by differing rates of response and adverse events. It is known that drug metabolism and drug toxicity may vary greatly between individuals, affecting both efficacy and toxicity. Strategies aimed at individualizing therapy would help to diminish this variability. Genetic variations might explain a proportion of this variability. In recent years, a number of associations between human genetic variants and predisposition to drug toxicity and risk of virologic failure have been described. These include the HLA class II allele $H L A-D R B^{*} 0101$ associated with nevirapine hypersensitivity, ${ }^{116,117} H L A-B * 5701$ with abacavir hypersensitivity reaction, ${ }^{18-121} \mathrm{CYP} 2 \mathrm{~B} 6$ alleles, with the central nervous system side effects of efavirenz, ${ }^{122-125}$ UGT1A1 alleles or polymorphisms in genes encoding for $\mathrm{P}$ glycoprotein both related to atazanavir-associated hyperbilirubinemia, ${ }^{126-128}$ and polymorphisms in genes encoding for transporter proteins with renal proximal tubulopathy in patients taking TDF. 7,12,93,95 Moreover, therapeutic drug monitoring may be helpful, allowing dose adjustments, especially when using a drug with a narrow therapeutic range, because small changes in drug levels lead to loss of efficacy and/or increased risk of toxicity. It may also be of aid in those cases in which information about drug interactions is still scarce, ie, for agents which have recently entered the marketplace. ${ }^{129-131}$

\section{Conclusion}

TDF is one of the most widely used antiretroviral drugs in clinical practice due to its potent antiviral activity, acceptable safety profile, and convenient administration.
The antiretroviral regimen currently recommended for initial therapy is the combination of TDF + emtricitabine, with addition of a convenient third agent, ie, efavirenz, raltegravir, or one of the newer ritonavir-boosted protease inhibitors (darunavir or atazanavir). TDF is also indicated in other situations, $t \mathrm{t}$ for replacing other nucleoside reverse transcriptase inhibitors in patients already with undetectable viremia, in an attempt to avoid or reverse the development of mitochondrial-related side effects, mainly lipoatrophy. TDF maintains its activity in most patients harboring drug-resistant variants, with only a few thymidine-associated mutations selected in prior episodes of treatment failure. Other situations in which TDF is being used include the treatment of patients coinfected with HIV and hepatitis B virus, and more recently, with great anticipation as part of pre-exposure prophylaxis. TDF is generally well tolerated in the short-term. However, a subset of individuals on prolonged TDF therapy may develop kidney tubular dysfunction and/or bone mineral loss. Periodic monitoring of renal function, in particular for tubular abnormalities, examining both plasma and urine biochemistry, may enable early recognition of individuals in whom the drug should be stopped to prevent more serious tubular damage and compromise of glomerular function. In this regard, information derived from pharmacogenetics and pharmacokinetics may help to identify the subset of individuals at greater risk for developing more severe renal injury.

\section{Disclosure}

The authors report no conflicts of interest in this work.

\section{References}

1. Gallo R, Montagnier L. The discovery of HIV as the cause of AIDS N Engl J Med. 2003;349:2283-2285.

2. Broder S, Gallo R. A pathogenic retrovirus (HTLV-III) linked to AIDS. N Engl J Med. 1984;311:1292-1297.

3. Tenofovir. Summary of product characteristics. Foster City, CA: Gilead Sciences; 2010

4. Fung HB, Stone EA, Piacenti FJ. Tenofovir disoproxil fumarate: A nucleotide reverse transcriptase inhibitor for the treatment of HIV infection. Clin Ther. 2002;24:34-45.

5. Cihlar T, Ho ES, Lin DC, Mulato AS. Human renal organic anion transporter 1 (hOAT1) and its role in the nephrotoxicity of antiviral nucleotide analogs. Nucleosides Nucleotides Nucleic Acids. 2001;20:641-648.

6. Ray A, Cihlar T, Robinson KL, et al. Mechanism of active renal tubular efflux of tenofovir. Antimicrob Agents Chemother. 2006;50: 3297-3304

7. Imaoka T, Kusuhara H, Adachi M, Schuetz JD, Takeuchi K, Sugiyama Y. Functional involvement of multidrug resistance-associated protein 4 (MRP4/ABCC4) in the renal elimination of the antiviral drugs adefovir and tenofovir. Mol Pharmacol. 2007;71:619-627.

8. Mallants R, Van Oosterwyck K, Van Vaeck L, Mols R, De Clercq E, Augustijns P. Multidrug resistance-associated protein 2 (MRP2) affects hepatobiliary elimination but not the intestinal disposition of tenofovir disoproxil fumarate and its metabolites. Xenobiotica. 2005;35: $1055-1066$. 
9. Miller DS. Nucleoside phosphonate interactions with multiple organic anion transporters in renal proximal tubule. J Pharmacol Exp Ther. 2001;299:567-574.

10. van Aubel RA, Smeets PH, Peters JG, Bindels RJ, Russel FG. The MRP4/ABCC4 gene encodes a novel apical organic anion transporter in human kidney proximal tubules: Putative efflux pump for urinary cAMP and cGMP. J Am Soc Nephrol. 2002;13:595-603.

11. Van Aubel R, Smeets PH, van den Heuvel JJ, Russel FG. Human organic anion transporter MRP4 (ABCC4) is an efflux pump for the purine end metabolite urate with multiple allosteric substrate binding sites. Am J Physiol Renal Physiol. 2005;288:F327-F333.

12. Pushpakom S, Liptrott N, Rodriguez-Novoa S. Genetic variants of ABCC10 are associated with kidney tubular dysfunction in patients treated with tenofovir-containing regimens. Abstr 742. Proceedings of the 17th Conference on Retroviruses and Opportunistic Infections, February 16-19, 2010, San Francisco, CA.

13. Ray AS, Olson L, Fridland A. Role of purine nucleoside phosphorylase in interactions between 2',3'-dideoxyinosine and allopurinol, ganciclovir, or tenofovir. Antimicrob Agents Chemother. 2004;48:1089-1095.

14. Kearney BP, Mathias A, Mittan A, Sayre J, Ebrahimi R, Cheng AK. Pharmacokinetics and safety of tenofovir disoproxil fumarate on coadministration with lopinavir/ritonavir. J Acquir Immune Defic Syndr. 2006;43:278-283.

15. Malan N, Su J, Mancini M, et al. Gastrointestinal tolerability and quality of life in antiretroviral-naive HIV-1-infected patients: Data from the CASTLE study. AIDS Care. 2010;22:677-686.

16. Taburet AM, Piketty $\mathrm{C}$, Chazallon $\mathrm{C}$, et al. Interactions between atazanavir-ritonavir and tenofovir in heavily pretreated HIV-infected patients. Antimicrob Agents Chemother. 2004;48:2091-2096.

17. Tong L, Phan TK, Robinson KL, et al. Effects of HIV protease inhibitors on the intestinal absorption of tenofovir disoproxil fumarate in vitro. Antimicrob Agents Chemother. 2007;51:3498-3504.

18. Kiser JJ, Carten ML, Aquilante CL, et al. The effect of lopinavir/ ritonavir on the renal clearance of tenofovir in HIV-infected patients. Clin Pharmacol Ther. 2008;83:265-272.

19. Cihlar T, Ray AS, Laflamme G, et al. Molecular assessment of the potential for renal drug interactions between tenofovir and HIV protease inhibitors. Antivir Ther. 2007;12:267-272.

20. Barrios A, Rendon A, Negredo E, et al. Paradoxical CD4+ T-cell decline in HIV-infected patients with complete virus suppression taking tenofovir and didanosine. AIDS. 2005;19:569-575.

21. Garcia-Benayas T, Rendon AL, Rodriguez-Novoa S, et al. Higher risk of hyperglycemia in HIV-infected patients treated with didanosine plus tenofovir. AIDS Res Hum Retroviruses. 2006;22:333-337.

22. Martinez E, Milinkovic A, de Lazzari E, et al. Pancreatic toxic effects associated with co-administration of didanosine and tenofovir in HIVinfected adults. Lancet. 2004;364:65-67.

23. Lopez S, Negredo E, Garrabou G, et al. Longitudinal study on mitochondrial effects of didanosine-tenofovir combination. AIDS Res Hum Retroviruses. 2006;22:33-39.

24. Arribas JR, Pozniak AL, Gallant JE, et al. Tenofovir disoproxil fumarate, emtricitabine, and efavirenz compared with zidovudine/ lamivudine and efavirenz in treatment-naive patients: 144-week analysis. J Acquir Immune Defic Syndr. 2008;47:74-78.

25. Cassetti I, Madruga JV, Suleiman JM, et al; Study 903E Team. The safety and efficacy of tenofovir DF in combination with lamivudine and efavirenz through 6 years in antiretroviral-naive HIV1-infected patients. HIV Clin Trials. 2007;8:164-172.

26. Gallant JE, Staszewski S, Pozniak AL, et al; 903 Study Group. Efficacy and safety of tenofovir DF vs stavudine in combination therapy in antiretroviral-naive patients: A 3-year randomized trial. JAMA. 2004;292:191-201.

27. Pozniak AL, Gallant JE, DeJesus E, et al. Tenofovir disoproxil fumarate, emtricitabine, and efavirenz versus fixed-dose zidovudine/ lamivudine and efavirenz in antiretroviral-naive patients: Virologic, immunologic, and morphologic changes: A 96-week analysis. J Acquir Immune Defic Syndr. 2006;43:535-540.
28. Schooley RT, Ruane P, Myers RA, et al. Tenofovir DF in antiretroviralexperienced patients: Results from a 48-week, randomized, double-blind study. AIDS. 2002;16:1257-1263.

29. Squires K, Pozniak AL, Pierone G, et al. Tenofovir disoproxil fumarate in nucleoside-resistant HIV-1 infection: A randomized trial. Ann Intern Med. 2003;139:313-320.

30. Martinez E, Arranz JA, Podzamczer D, et al; BICOMBO Study Team. A simplification trial switching from nucleoside reverse transcriptase inhibitors to once-daily fixed-dose abacavir/lamivudine or tenofovir/ emtricitabine in HIV-1-infected patients with virological suppression. J Acquir Immune Defic Syndr. 2009;51:290-297.

31. Post FA, Moyle GJ, Stellbrink HJ, et al. Randomized comparison of renal effects, efficacy, and safety with once-daily abacavir/lamivudine versus tenofovir/emtricitabine, administered with efavirenz, in antiretroviral-naive, HIV-1-infected adults: 48-week results from the ASSERT study. J Acquir Immune Defic Syndr. 2010;55:49-57.

32. Sax PE, Tierney C, Collier AC, et al; AIDS Clinical Trials Group Study A5202 Team. Abacavir-lamivudine versus tenofovir-emtricitabine for initial HIV-1 therapy. N Engl J Med. 2009;361:2230-2240.

33. Martin A, Bloch M, Amin J, et al. Simplification of antiretroviral therapy with tenofovir-emtricitabine or abacavir-lamivudine: A randomized, 96-week trial. Clin Infect Dis. 2009;49:1591-1601.

34. Moyle GJ, Sabin CA, Cartledge J, et al; RAVE (Randomized Abacavir versus Viread Evaluation) Group UK. A randomized comparative trial of tenofovir DF or abacavir as replacement for a thymidine analogue in persons with lipoatrophy. AIDS. 2006;20:2043-2050.

35. Smith KY, Patel P, Fine D, et al; HEAT Study Team. Randomized, double-blind, placebo-matched, multicenter trial of abacavir/ lamivudine or tenofovir/emtricitabine with lopinavir/ritonavir for initial HIV treatment. AIDS. 2009;23:1547-1556.

36. Wainberg MA, Miller MD, Quan Y, et al. In vitro selection and characterization of HIV-1 with reduced susceptibility to PMPA. Antivir Ther. 1999;4:87-94.

37. McColl DJ, Margot NA, Wulfsohn M, Coakley D, Cheng A, Miller M. Patterns of resistance emerging in HIV-1 from antiretroviral-experienced patients undergoing intensification therapy with tenofovir disoproxil fumarate. J Acquir Immune Defic Syndr. 2004;37:1340-1350.

38. Von WV, Yerly S, Boni J, et al. Factors associated with the emergence of $\mathrm{K} 65 \mathrm{R}$ in patients with HIV-1 infection treated with combination antiretroviral therapy containing tenofovir. Clin Infect Dis. 2008;46: 1299-1309.

39. Gallant JE, DeJesus E, Arribas JR, et al; 934 Study Group. Tenofovir DF, emtricitabine, and efavirenz vs zidovudine, lamivudine, and efavirenz for HIV. N Engl J Med. 2006;354:251-260.

40. Stellbrink HJ, Orkin C, Arribas JR. Comparison of changes in bone density and turnover with abacavir-lamivudine versus tenofoviremtricitabine in HIV-infected adults: 48-week results from the ASSERT study. Clin Infect Dis. 2010;51:963-972.

41. Estrada V, Fuster M. Darunavir in treatment-naive patients. The ARTEMIS study. Enferm Infecc Microbiol Clin. 2008;26 Suppl 10: S10-S13. Spanish.

42. Johnson M, Grinsztejn B, Rodriguez C, et al. 96-week comparison of once-daily atazanavir/ritonavir and twice-daily lopinavir/ritonavir in patients with multiple virologic failures. AIDS. 2006;20:711-718.

43. Molina JM, Andrade-Villanueva J, Echevarria J, et al; CASTLE Study Team. Once-daily atazanavir/ritonavir compared with twice-daily lopinavir/ritonavir, each in combination with tenofovir and emtricitabine, for management of antiretroviral-naive HIV-1-infected patients: 96-week efficacy and safety results of the CASTLE study. J Acquir Immune Defic Syndr. 2010;53:323-332.

44. Smith K, Weinberg W, DeJesus E, et al. Fosamprenavir or atazanavir once daily boosted with ritonavir $100 \mathrm{mg}$, plus tenofovir/emtricitabine, for the initial treatment of HIV infection: 48-week results of ALERT. AIDS Res Ther. 2008;28:5.

45. Walmsley S, Avihingsanon A, Slim J, et al. Gemini: A non-inferiority study of saquinavir/ritonavir versus lopinavir/ritonavir as initial HIV-1 therapy in adults. J Acquir Immune Defic Syndr. 2009;50:367-374. 
46. Izzedine H, Hulot JS, Vittecoq D, et al. Long-term renal safety of tenofovir disoproxil fumarate in antiretroviral-naive HIV-1-infected patients. Data from a double-blind randomized active-controlled multicentre study. Nephrol Dial Transplant. 2005;20:743-746.

47. Nelson MR, Katlama C, Montaner JS, et al. The safety of tenofovir disoproxil fumarate for the treatment of HIV infection in adults: The first 4 years. AIDS. 2007;21:1273-1281.

48. Zimmermann AE, Pizzoferrato T, Bedford J, Morris A, Hoffman R, Braden G. Tenofovir-associated acute and chronic kidney disease A case of multiple drug interactions. Clin Infect Dis. 2006;42: 283-290.

49. Parsonage MJ, Wilkins EG, Snowden N, Issa BG, Savage MW. The development of hypophosphataemic osteomalacia with myopathy in two patients with HIV infection receiving tenofovir therapy. HIV Med. 2005;6:341-346.

50. Madeddu G, Bonfanti P, De Socio GV, et al. Tenofovir renal safety in HIV-infected patients: Results from the SCOLTA project. Biomed Pharmacother. 2008;62:6-11.

51. Jones R, Stebbing J, Nelson M, et al. Renal dysfunction with tenofovir disoproxil fumarate-containing highly active antiretroviral therapy regimens is not observed more frequently: A cohort and case-control study. J Acquir Immune Defic Syndr. 2004;37:1489-1495.

52. Gallant JE, Parish MA, Keruly JC, Moore RD. Changes in renal function associated with tenofovir disoproxil fumarate treatment, compared with nucleoside reverse-transcriptase inhibitor treatment. Clin Infect Dis. 2005;40:1194-1198.

53. Gerard L, Chazallon C, Taburet AM, Girard PM, Aboulker JC, Piketty C. Renal function in antiretroviral-experienced patients treated with tenofovir disoproxil fumarate associated with atazanavir/ritonavir Antivir Ther. 2007;12:31-39.

54. Goicoechea M, Liu S, Best B, et al. Greater tenofovir-associated renal function decline with protease inhibitor-based versus nonnucleoside reverse-transcriptase inhibitor-based therapy. J Infect Dis. 2008;197: $102-108$.

55. Mauss S, Berger F, Schmutz G. Antiretroviral therapy with tenofovir is associated with mild renal dysfunction. AIDS. 2005;19:93-95.

56. Kinai E, Hanabusa H. Progressive renal tubular dysfunction associated with long-term use of tenofovir DF. AIDS Res Hum Retroviruses. 2009;25:387-394.

57. Winston A, Amin J, Mallon P, et al. Minor changes in calculated creatinine clearance and anion-gap are associated with tenofovir disoproxil fumarate-containing highly active antiretroviral therapy. HIV Med. 2006;7:105-111.

58. Fux CA, Simcock M, Wolbers M, et al. Tenofovir use is associated with a reduction in calculated glomerular filtration rates in the Swiss HIV Cohort Study. Antivir Ther. 2007;12:1165-1173.

59. Mocroft A, Kirk O, Gatell J, et al. Chronic renal failure among HIV1-infected patients. AIDS. 2007;21:1119-1127.

60. Bpharm S, Talbot A, Trottier B. Acute renal failure in four HIV-infected patients: Potential association with tenofovir and non-steroidal anti-inflammatory drugs. Can J Infect Dis Med Microbiol. 2008;19:75-76.

61. Coca S, Perazella M. Rapid communication: Acute renal failure associated with tenofovir: evidence of drug-induced nephrotoxicity. Am J Med Sci. 2002;324:342-344.

62. Izzedine H, Baumelou A, Deray G. Acute renal failure in HIV patients. Nephrol Dial Transplant. 2007;22:2757-2762.

63. Kapitsinou PP, Ansari N. Acute renal failure in an AIDS patient on tenofovir: A case report. J Med Case Reports. 2008;2:94.

64. Vallecillo-Sanchez G, Guelar-Grimberg A, Gonzalez-Mena A, Knobel-Freud $\mathrm{H}$. Acute renal failure associated with the use of tenofovir combined with atazanavir in patients with HIV infection. Enferm Infecc Microbiol Clin. 2008;26:316-317. Spanish.

65. Malik A, Abraham P, Malik N. Acute renal failure and Fanconi syndrome in an AIDS patient on tenofovir treatment - case report and review of literature. $J$ Infect. 2005;51:E61-E65.

66. Dupont C, Meier F, Loupy A, Page B, Rouveix E. Acute renal failure and tenofovir: Two new cases. Antivir Ther. 2003;8(Suppl 1):76.
67. Wood SM, Shah SS, Steenhoff AP, Meyers KE, Kaplan BS, Rutstein RM. Tenofovir-associated nephrotoxicity in two HIV-infected adolescent males. AIDS Patient Care STDS. 2009;23:1-4.

68. Callens S, De Roo A, Colebunders R. Fanconi-like syndrome and rhabdomyolysis in a person with HIV infection on highly active antiretroviral treatment including tenofovir. $J$ Infect. 2003;47:262-263.

69. Verhelst D, Monge M, Meynard JL, et al. Fanconi syndrome and renal failure induced by tenofovir: A first case report. Am J Kidney Dis. 2002;40:1331-1333.

70. Creput C, Gonzalez-Canali G, Hill G, Piketty C, Kazatchkine M, Nochy D. Renal lesions in HIV-1-positive patient treated with tenofovir. AIDS. 2003;17:935-937.

71. Irizarry-Alvarado JM, Dwyer JP, Brumble LM, Alvarez S, Mendez JC. Proximal tubular dysfunction associated with tenofovir and didanosine causing Fanconi syndrome and diabetes insipidus: A report of 3 cases. AIDS Read. 2009;19:114-121.

72. Karras A, Lafaurie M, Furco A, et al. Tenofovir-related nephrotoxicity in human immunodeficiency virus-infected patients: Three cases of renal failure, Fanconi syndrome, and nephrogenic diabetes insipidus. Clin Infect Dis. 2003;36:1070-1073.

73. Mathew G, Knaus SJ. Acquired Fanconi's syndrome associated with tenofovir therapy. $J$ Gen Intern Med. 2006;21:C3-C5.

74. Peyriere H, Reynes J, Rouanet I, et al. Renal tubular dysfunction associated with tenofovir therapy: Report of 7 cases. JAcquir Immune Defic Syndr. 2004;35:269-273.

75. Rifkin BS, Perazella MA. Tenofovir-associated nephrotoxicity: Fanconi syndrome and renal failure. Am J Med. 2004;117:282-284.

76. Rollot F, Nazal EM, Chauvelot-Moachon L, et al. Tenofovirrelated Fanconi syndrome with nephrogenic diabetes insipidus in a patient with acquired immunodeficiency syndrome: The role of lopinavir-ritonavir-didanosine. Clin Infect Dis. 2003;37:e174-e176.

77. Labarga P, Barreiro P, Martin-Carbonero L, et al. Kidney tubular abnormalities in the absence of impaired glomerular function in HIV patients treated with tenofovir. AIDS. 2009;23:689-696.

78. De la Prada FJ, Prados AM, Tugores A, Uriol M, Saus C, Morey A. Acute renal failure and proximal renal tubular dysfunction in a patient with acquired immunodeficiency syndrome treated with tenofovir. Nefrologia. 2006;26:626-630. Spanish.

79. Di Biagio A, Rosso R, Monteforte P, Russo R, Rovetta G, Viscoli C. Whole body bone scintigraphy in tenofovir-related osteomalacia: A case report. J Med Case Reports. 2009;3:8136.

80. Woodward CL, Hall AM, Williams IG, et al. Tenofovir-associated renal and bone toxicity. HIV Med. 2009;10:482-487.

81. Childs KE, Fishman SL, Constable C, et al. Short communication: Inadequate vitamin $\mathrm{D}$ exacerbates parathyroid hormone elevations in tenofovir users. AIDS Res Hum Retroviruses. 2010;26:855-859.

82. Rosenvinge MM, Gedela K, Copas AJ, et al. Tenofovir-linked hyperparathyroidism is independently associated with the presence of vitamin D deficiency. J Acquir Immune Defic Syndr. 2010; 54:496-499.

83. Schaaf B, Aries SP, Kramme E, Steinhoff J, Dalhoff K. Acute renal failure associated with tenofovir treatment in a patient with acquired immunodeficiency syndrome. Clin Infect Dis. 2003;37:e41-e43.

84. Wever K, van Agtmael MA, Carr A. Incomplete reversibility of tenofovir-related renal toxicity in HIV-infected men. J Acquir Immune Defic Syndr. 2010;55:78-81.

85. Judd A, Boyd KL, Stohr W, et al. Effect of tenofovir disoproxil fumarate on risk of renal abnormality in HIV-1-infected children on antiretroviral therapy: A nested case-control study. AIDS. 2010;24:525-534.

86. Soler-Palacin P, Melendo S, Noguera-Julian A, et al. Prospective study of renal function in HIV-infected pediatric patients receiving tenofovir-containing HAART regimens. AIDS. 2011;25:171-176.

87. Rosso R, Parodi A, Torrisi C, De Terlizzi F, Viscoli C, Vignolo M. A tailored dose of tenofovir could reduce its impact on bone mass in HIV Type 1-infected children and adolescents: A report from 5 years of clinical experience. AIDS Res Hum Retroviruses. 2010;26: $1265-1266$. 
88. Riordan A, Judd A, Boyd K, Cliff D, et al. Tenofovir use in human immunodeficiency virus-1-infected children in the United Kingdom and Ireland. Pediatr Infect Dis J. 2009;28:204-209.

89. Purdy JB, Gafni RI, Reynolds JC, Zeicher S, Hazra R. Decreased bone mineral density with off-label use of tenofovir in children and adolescents infected with human immunodeficiency virus. J Pediatr. 2008;152:582-584.

90. Gafni RI, Hazra R, Reynolds JC, et al. Tenofovir disoproxil fumarate and an optimized background regimen of antiretroviral agents as salvage therapy: Impact on bone mineral density in HIV-infected children. Pediatrics. 2006;118:e711-e718.

91. Barrios A, Garcia-Benayas T, Gonzalez-Lahoz J, Soriano V. Tenofovir-related nephrotoxicity in HIV-infected patients. AIDS. 2004; 18:960-963.

92. Gupta SK. Tenofovir-associated Fanconi syndrome: Review of the FDA adverse event reporting system. AIDS Patient Care STDS. 2008; 22:99-103

93. Rodriguez-Novoa S, Labarga P, Soriano V. Pharmacogenetics of tenofovir treatment. Pharmacogenomics. 2009;10:1675-1685.

94. Izzedine H, Hulot JS, Villard E, et al. Association between $\mathrm{ABCC} 2$ gene haplotypes and tenofovir-induced proximal tubulopathy. J Infect Dis. 2006;194:1481-1491.

95. Rodriguez-Novoa S, Labarga P, Soriano V, et al. Predictors of kidney tubular dysfunction in HIV-infected patients treated with tenofovir: A pharmacogenetic study. Clin Infect Dis. 2009;48:e108-e116.

96. Ter Heine R, Huitema AD, Jansen RS, et al. Prolonged exposure to tenofovir monotherapy 1 month after treatment discontinuation because of tenofovir-related renal failure. Antivir Ther. 2009;14:299-301.

97. Rodriguez-Novoa S, Labarga P, D'avolio A, et al. Impairment in kidney tubular function in patients receiving tenofovir is associated with higher tenofovir plasma concentrations. AIDS. 2010;24:1064-1066.

98. Young B, Dao CN, Buchacz K, Baker R, Brooks JT. Increased rates of bone fracture among HIV-infected persons in the HIV Outpatient Study (HOPS) compared with the US general population, 2000-2006. Clin Infect Dis. 2011;52:1061-1068.

99. Brown TT, Qaqish RB. Antiretroviral therapy and the prevalence of osteopenia and osteoporosis: A meta-analytic review. AIDS. 2006;20: 2165-2174.

100. Grund B, Peng G, Gibert CL, et al. Continuous antiretroviral therapy decreases bone mineral density. AIDS. 2009;23:1519-1529.

101. Tebas P, Powderly WG, Claxton S, et al. Accelerated bone mineral loss in HIV-infected patients receiving potent antiretroviral therapy. AIDS. 2000;14:F63-F67.

102. Amiel C, Ostertag A, Slama L, et al. BMD is reduced in HIV-infected men irrespective of treatment. J Bone Miner Res. 2004;19:402-409.

103. Holick MF. Vitamin D deficiency. N Engl J Med. 2007;357:266-281.

104. Labarga P, Barreiro P, Martin-Carbonero L, et al. Prevalence and mechanisms of hyperparathyroidism in HIV+ patients treated with TDF. Abstr 824. Proceedings of the 18th Conference on Retroviruses and Opportunistic Infections, Boston, MA, February 27-March 2, 2011.

105. Steingrimsdottir L, Gunnarsson O, Indridason OS, Franzson L, Sigurdsson G. Relationship between serum parathyroid hormone levels, vitamin D sufficiency, and calcium intake. JAMA. 2005;294: 2336-2341.

106. Rodriguez M, Daniels B, Gunawardene S, Robbins GK. High frequency of vitamin D deficiency in ambulatory HIV-positive patients. AIDS Res Hum Retroviruses. 2009;25:9-14.

107. Pocaterra D, Carenzi L, Ricci E, et al. TDF therapy is independently associated to hyperparathyroidism in HIV-infected treated patients. Abstr 825. Proceedings of the 18th Conference on Retroviruses and Opportunistic Infections, Boston, MA, February 27-March 2, 2011.

108. Havens P, Hazra R, Stephensen C, et al. Vitamin D3 supplementation decreases PTH in HIV-infected youth being treated with TDF-containing combination ART: A randomized, double-blind, placebo-controlled multicenter trial: Adolescent Trials Network Study 063. Abstr 80. Proceedings of the 18th Conference on Retroviruses and Opportunistic Infections, Boston, MA, February 27-March 2, 2011.
109. Abdool KQ, Abdool SS, Frohlich JA, et al; CAPRISA004 Trial Group. Effectiveness and safety of tenofovir gel, an antiretroviral microbicide, for the prevention of HIV infection in women. Science. 2010;329: 1168-1174.

110. Grant RM, Lama JR, Anderson PL, et al; iPrEx Study Team. Preexposure chemoprophylaxis for HIV prevention in men who have sex with men. N Engl J Med. 2010;363:2587-2599.

111. Benhamou Y, Tubiana R, Thibault V. Tenofovir disoproxil fumarate in patients with HIV and lamivudine-resistant hepatitis B virus. N Engl J Med. 2003;348:177-178.

112. Soriano V, Puoti M, Peters M, et al. Care of HIV patients with chronic hepatitis B: Updated recommendations from the HIV-Hepatitis B Virus International Panel. AIDS. 2008;22:1399-1410.

113. Tan J, Degertekin B, Wong SN, Husain M, Oberhelman K, Lok AS. Tenofovir monotherapy is effective in hepatitis B patients with antiviral treatment failure to adefovir in the absence of adefovir-resistant mutations. J Hepatol. 2008;48:391-398.

114. Puoti M, Airoldi M, Bruno R, et al. Hepatitis B virus co-infection in human immunodeficiency virus-infected subjects. AIDS Rev. 2002;4:27-35.

115. Panel of Antiretroviral Guidelines for Adults and Adolescents. Guidelines for the use of antiretroviral agents in HIV-1 infected adults and adolescents; 1-166. Department of Health and Human Services. January 10, 2011. Available at: http://aidsinfo.nih.gov/guidelines. Accessed May 10, 2011.

116. Gatanaga H, Yazaki H, Tanuma J, et al. HLA-Cw8 primarily associated with hypersensitivity to nevirapine. AIDS. 2007;21:264-265.

117. Littera R, Carcassi C, Masala A, et al. HLA-dependent hypersensitivity to nevirapine in Sardinian HIV patients. AIDS. 2006;20: 1621-1626.

118. Hetherington S, McGuirk S, Powell G, et al. Hypersensitivity reactions during therapy with the nucleoside reverse transcriptase inhibitor abacavir. Clin Ther. 2001;23:1603-1614.

119. Hetherington S, Hughes AR, Mosteller M, et al. Genetic variations in HLA-B region and hypersensitivity reactions to abacavir. Lancet. 2002;359:1121-1122.

120. Mallal S, Nolan D, Witt C, et al. Association between presence of HLA-B*5701, HLA-DR7, and HLA-DQ3 and hypersensitivity to HIV-1 reverse-transcriptase inhibitor abacavir. Lancet. 2002;359: 727-732.

121. Mallal S, Phillips E, Carosi G, et al. HLA-B*5701screening for hypersensitivity to abacavir. $N$ Engl J Med. 2008;358:568-579.

122. Haas DW, Ribaudo HJ, Kim RB, et al. Pharmacogenetics of efavirenz and central nervous system side effects: An Adult AIDS Clinical Trials Group study. AIDS. 2004;18:2391-2400.

123. Rodriguez-Novoa S, Barreiro P, Rendon A, et al. Influence of $516 \mathrm{G}>\mathrm{T}$ polymorphisms at the gene encoding the CYP450-2B6 isoenzyme on efavirenz plasma concentrations in HIV-infected subjects. Clin Infect Dis. 2005;40:1358-1361.

124. Rotger M, Colombo S, Furrer H, et al. Influence of CYP2B6 polymorphism on plasma and intracellular concentrations and toxicity of efavirenz and nevirapine in HIV-infected patients. Pharmacogenet Genomics. 2005;15:1-5.

125. Rotger M, Tegude H, Colombo S, et al. Predictive value of known and novel alleles of CYP2B6 for efavirenz plasma concentrations in HIV-infected individuals. Clin Pharmacol Ther. 2007;81: W557-W566.

126. Rodriguez-Novoa S, Martin-Carbonero L, Barreiro P, et al. Genetic factors influencing atazanavir plasma concentrations and the risk of severe hyperbilirubinemia. AIDS. 2007;21:41-46.

127. Rodriguez-Novoa S, Barreiro P, Rendon A, et al. Plasma levels of atazanavir and the risk of hyperbilirubinemia are predicted by the $3435 \mathrm{C}>\mathrm{T}$ polymorphism at the multidrug resistance gene 1 . Clin Infect Dis. 2006;42:291-295.

128. Rotger M, Taffe P, Bleiber G, et al. Gilbert syndrome and the development of antiretroviral therapy-associated hyperbilirubinemia. J Infect Dis. 2005;192:1381-1386. 
129. Back DJ, Khoo SH, Gibbons SE, Barry MG, Merry C. Therapeutic drug monitoring of antiretrovirals in human immunodeficiency virus infection. Ther Drug Monit. 2000;22:122-126.

130. Brown KC, Paul S, Kashuba AD. Drug interactions with new and investigational antiretrovirals. Clin Pharmacokinet. 2009;48:211-241.
131. Duong M, Golzi A, Peytavin G, et al. Usefulness of therapeutic drug monitoring of antiretrovirals in routine clinical practice. HIV Clin Trials. 2004;5:216-223.

Virus Adaptation and Treatment

\section{Publish your work in this journal}

Virus Adaptation and Treatment is an international, peer-reviewed open access journal focusing on the study of virology, viral adaptation and the development and use of antiviral drugs and vaccines to achieve improved outcomes in infection control and treatment. The journa welcomes original research, basic science, clinical \& epidemiological
Dovepress

studies, reviews \& evaluations, expert opinion and commentary, case reports and extended reports. The manuscript management system is completely online and includes a very quick and fair peer-review system, which is all easy to use. Visit http://www.dovepress.com/ testimonials.php to read real quotes from published authors.

Submit your manuscript here: http://www.dovepress.com/virus-adaptation-and-treatment-journal 